\title{
Application of Comprehensive Fall Index Method in Water Level-Flow Relation of Main Cross Sections in Middle Reaches of the Yangtze River
}

\author{
Wan Fengming ${ }^{1,2, a}$, Long Lihua ${ }^{3, b}$ \\ ${ }^{1}$ Wuhan University of Technology, Wuhan, China \\ ${ }^{2}$ Hubei Business College, Wuhan, China \\ ${ }^{3}$ HuBei Water Resources Technical College, Wuhan, China \\ a564017119@qq.com, ${ }^{b} 1024025148 @ q q . c o m$
}

\begin{abstract}
Keywords: Water Level-Flow Relation; Comprehensive Fall Index Method; Principle of Least Squares; Polynomial Fitting

Abstract: The Yangtze River, the longest river in China, is also a famous river in the world. Most regions within its drainage basin are of moderate climate, abundant rainfall, rich resources and dense population, in the meantime, the Yangtze River basin is also a region in which floods frequently happens. In order to launch studies on flood control impact in the middle reaches of the Yangtze River better, this paper selected stage-discharge data of the main fracture surfaces of three control stations-Shashi, Luoshan and Hankou located on middle reaches of the Yangtze River during flood period (from May to September) during 1981 2010, based on analysis of influencing factors on water level-flow relations in three hydrologic sections, it adopted comprehensive fall index method to process these data, by which it obtained the achievement of water level-flow relation curves in these stations, and used principle of least squares to conduct curve fitting and then made a reasonable analysis. Results show that polynomial curves fitting can eliminate the influence of calculated water level-flow relation line to the least, and it has better effect in practical application.
\end{abstract}

\section{Introduction}

The Yangtze River basin is a region in which floods frequently happens within China, especially within 126,000 sq. km. on plain area of the middle and lower reaches of Yangtze River, floods are more frequent and serious. Flood in 1998 and severe flood prevention and control situation in recent years have further revealed problems existing in flood prevention and control on middle reaches of Yangtze River. Hence, it's quite necessary to launch studies on flood control impact on middle reaches of Yangtze River.

In order to adapt to dynamic change process of the Yangtze River and conform to basic principles of hydrological data acquisition, this study adopted measured data at the end of the last century and at the turn of this century, namely daily average water level and flow data of the main cross section of middle reaches of the Yangtze River during flood period (from May to September) during 1981 2010 to conduct analysis and calculation with comprehensive fall index method, obtained water level-flow relation curves in three stations-Shashi, Luoshan and Hankou, and explored change rules by analyzing station characteristics to estimate developmental tendencies in the future.

\section{Study of Influencing Factors on Water Level-Flow Relations of Stations}

\section{Shashi Station}

Shashi gauging station is $67.4 \mathrm{~km}$ away to the north of Xinchang station, $76.1 \mathrm{~km}$ from Ouchikou and $241.9 \mathrm{~km}(324.7 \mathrm{~km}$ before bend cutting) from Chenglingji. Shashi-Xinchang reach has no branch inflow or dam burst distribution, and calming effect of flood after riverway regulation and storage is slight.

Jingjiang River bend cutting during 1967 1972 caused systematic change of water level-flow relation in this station. According to riverway features, flood composition and cross section analysis 
in Jingjiang reach, it's believed that water level-flow relation in Shashi station are mainly influenced by the following factors: cross section scouring and silting variation, Chenglingji water level, backwater jacking of lower-reach variation, fluctuation rate of flood, etc., cross section water level-area relation in Shashi station is the primary factor. Besides above factors, there are also flood composition of Jingjiang River and Dongting Lake, continuous floods, water level of flood rising, flood peak shape, etc.

\section{Luoshan Station}

Luoshan hydrological station is $3.5 \mathrm{~km}$ to the south of outlet of Dongting Lake and it's a control station for Dongting Lake effluent and Jingjiang River inflow. Lushui River, which is $35 \mathrm{~km}$ downward Luoshan, flows into Yangtze River at Luxikou. Han River, the longest branch of Yangtze River, is $210 \mathrm{~km}$ away from downstream of Luoshan and it flows into Yangtze River in Wuhan City. In the meantime, there are also Jinshui, Sheshui, Daoshui, Jushui, Fushui, Huiyuanjou, Bashui, Xishui, Qishui and so on in the downstream to uplift it. Fluctuation of these branches has a certain influence on water level and flow in Luoshan station.

According to natural features of Hankou segment, flood composition features and cross sectional water level-area relation in Lianhuatang station and water level-flow relation loop curve analysis, it's found that factors influencing Luoshan water level-flow relation are quite complicated, mainly including scouring and silting variation, river reach scouring and silting variation, downstream variation backwater effect, flood fluctuation, etc.,[1] secondly, flood composition in stem stream and branches as well as evolution of river and lake relation and so on has a certain influence.

\section{Hankou Station}

Han River which is $1.4 \mathrm{~km}$ upward Hankou station flows into Yangtze River at the left bank of Han River, and more upward, there are Dongjing River, Jinshui and Lushui flowing into Yangtze River; Fuhuan River at the left bank which is $9.2 \mathrm{~km}$ downward Hankou station flows into Yangtze River, and more downward, there are Daoshui, Jushui, Bashui, Xishui, Qishui, Wuhu and Zhangdu Lake flowing into the stem stream, and at the right bank, Liangzi Lake and Fushui joining the stream. Poyang Lake drainage system which is $284 \mathrm{~km}$ downward the station flows into Yangtze River at outlet. Downstrean branches inflow have a certain backwater effect on water level-flow relation in this station.

Main factors influencing water level-flow relation in Hankou Station include: backwater effect of downstream branch variation, flood fluctuation, cross section scouring and silting variation, and special water regimens like flood encounter of stem stream and branches, continuous multi-peak flood, flood diversion dam burst, etc.[2]

\section{Calculation Principle and Method of Water Level-Relation Curve Fitting}

In recent years, in terms of determination of water, there has been a large number of researches which have proposed comprehensive unit hydrograph method, fall index method, downstream water-level parameter method, etc.[3] Traditional establishment of water level-flow relation curve has always used temporary curve method, but this aligning method can be influenced by many human factors. Because of difference in practical working experience, and with different parameters taken into consideration, parameters can't be quantified, consequently, relation curves given by different people will be different. And calculated flow quantities will be of different values, which brings inconveniences to practical work. However, appropriate mathematical model which is used to do curve fitting can solve this problem.

Based on previous researches, this paper, according to practical situation, conduced statistical analysis of water level and flow at 8:00 every day during flood period (from May to September) during 1981 2010 in Shashi, Luoshan and Hankou stations, based on which it used principle of the least squares to do curve fitting. Polynomials used, the influence of individual measuring points with large testing errors was eliminated to the least. As relation lines were calculated by mathematical 
formula, flow quantities deducted by relation lines would not be different because of difference in alignment. In practical application, it has better effect.

\section{Shashi Station:}

Shashi water level-flow relation is under effect of backwater variations like flood fluctuation, water level of Lianhuatang, effluent of Dongting Lake, etc, hence, fitting of Shashi water level-flow relation in the 90 s put emphasis on these factors.

(1) Reform of Flood Fluctuation Influence

Because of the influence of above factors, measured flow points sometimes present as anticlockwise loop curve, and sometimes are quite dispersive, and the two factors are mixed together. In order to differentiate the two kinds of influencing factors, flood in stem stream of Yangtze River is large while Dongting Lake inflow is small, and backwater effect is not obvious. 1981, 1987 and 1989 data were analyzed, correction factor method was used to correct flood fluctuation, floods in above three years presented obvious loop curves. When correction factors were taken among 10000 20000, correction effect was better, high water points were obviously concentrated with densely concentrated point groups. With full consideration of its correction factor 1/UI, when 15000 was taken, the effect was better. The following equation was used for correction of flood fluctuation rate.

$$
Q_{c}=\frac{Q_{n}}{\sqrt{1+\frac{\Delta Z}{\Delta t} \cdot \frac{1}{U I_{c}}}}
$$

$\mathrm{Q}_{\mathrm{c}}$------steady flow after correction $\left(\mathrm{m}^{3} / \mathrm{s}\right)$;

$\mathrm{Q}_{\mathrm{n}}$------ measured flow $\left(\mathrm{m}^{3} / \mathrm{s}\right)$;

$\mathrm{Z}$------ rising or falling flood water level of one day $(\mathrm{m})$;

$\mathrm{t}$------time bucket,one day=86400s;

1/UI $\mathrm{U}_{\mathrm{c}}$------correction factor, Shashi station is 15000 after the optimization。

(2) Analysis of backwater effect of Lianhuatang

Through reorganization of measured data in Shashi station and Lianhuatang at the same time, it's found that its water level-flow relation was related to water level in Lianhuatang. When water level in Lianhuatang was low, Shashi station was mainly influenced by flood fluctuation and cross section scouring and silting, and water level-flow point groups were relatively concentrated; when Dongting Lake effluent was large and water level in Lianhuatang was high, Shashi station was mainly influenced by backwater effect with much water level elevation (such as in 1996 and 1998) and dispersive point groups).[4]

Corresponding water levels in Lianhuatang was taken as parameter points to draw diagram of $1981 \sim 2003$ water level-flow measuring points in Shashi station, and it's found that originally dispersive points presented regular distribution with variation of water levels in Lianhuatang. Measuring points with high water level in Lianhuatang were above and those with low levels were below. We used the following equation to analyze influence of Lianhuatang water level, and obtained water level-flow relation results in Shashi station (as shown in Table 1).

$$
Q_{c}=C\left(H_{S}-H_{L}-0.21\right)^{n}
$$

$Q_{c}$ steady flow after correction of Shashi station $(\mathrm{m} 3 / \mathrm{s})$;

$C$ _ correlation coefficient of the relationship between stage and discharge in Shashi station, calculated by the measured data;

$H_{S} 、 H_{L} \longrightarrow$ water level of Shashi and Lianhuatang (m);

$\mathrm{n}-$ Coefficient of minimum error calculated by using least square method considering the relationship of $H_{S}$ and $C$. 
Tablel: The stage-discharge relationship results of Shashi(water level: $\mathrm{m}$; flow rate: $\mathrm{m}^{3} / \mathrm{s}$ )

\begin{tabular}{|c|c|c|c|c|c|c|c|c|c|c|c|}
\hline$f_{Z}$ & \multicolumn{11}{|c|}{ the flaw which water leval of Lianhuatang station corresponding } \\
\hline & 26 & 27 & 28 & 29 & 30 & 31 & 32 & 33 & 34 & 35 & 36 \\
\hline 33 & 3560 & 2350 & & & & & & & & & \\
\hline 34 & 6330 & 5060 & 3810 & 2590 & & & & & & & \\
\hline 35 & 9400 & 8170 & 6830 & 5620 & 4350 & 3060 & & & & & \\
\hline 36 & 12670 & 11420 & 10170 & 8750 & 7420 & 6080 & 4930 & 3640 & & & \\
\hline 37 & 16580 & 15170 & 13940 & 12330 & 10920 & 9580 & 8250 & 6920 & 5420 & 4000 & \\
\hline 38 & 21000 & 19490 & 18050 & 16500 & 15000 & 13420 & 12080 & 10670 & 9170 & 7580 & 6100 \\
\hline 39 & 26420 & 24670 & 23030 & 21330 & 19580 & 18080 & 16580 & 15000 & 13330 & 11830 & 10300 \\
\hline 40 & 32670 & 30750 & 28850 & 26830 & 24920 & 23080 & 21330 & 19670 & 18000 & 16250 & 14750 \\
\hline 41 & 40080 & 37830 & 35590 & 33330 & 31170 & 29170 & 27170 & 25080 & 23250 & 21420 & 19830 \\
\hline 42 & 47750 & 45500 & 43180 & 40580 & 38250 & 35750 & 33580 & 31330 & 29170 & 27250 & 25330 \\
\hline 43 & 56490 & 53920 & 51170 & 48420 & 45750 & 43170 & 40750 & 38330 & 35920 & 33750 & 31580 \\
\hline 44 & 65750 & 62920 & 60000 & 56920 & 53830 & 51000 & 48500 & 45920 & 43420 & 41000 & 38670 \\
\hline 45 & 75140 & 71920 & 68710 & 65330 & 62330 & 59420 & 56530 & 53960 & 51530 & 48960 & 46320 \\
\hline 46 & & 81000 & 77630 & 74580 & 71250 & 68000 & 65260 & 62350 & 59640 & 56940 & 54300 \\
\hline 47 & & & & & & & & 70510 & 67690 & 65240 & 62350 \\
\hline
\end{tabular}

\section{Luoshan Station and Hankou Station:}

Water level-flow relations in Luoshan station and Hankou station are mainly influenced by factors like downstream branches backwater effect, flood fluctuation, etc. which will be analyzed as follows.

Correction of Flood Fluctuation Influence

Influenced by additional gradients of flood waves, measured water level-flow relation in Luoshan station is influenced by flood fluctuation rate and presents as anticlockwise loop curve. Hence, correction factor method can be used to correct water level-flow relation influenced by flood fluctuation rate. Based on analysis of flooding years since the 1980s, we compared correction effects of different correction factors on water level-flow relation loop curves, and we found that optimal correction factors in different years were slightly different. [5]With full consideration of the correction factor 1/UI, when it was 40,000 in Luoshan station and Hankou station, the effect would be better.

Equation (1) was used to calculate flood fluctuation rate correction, and correction factor 1/UI was taken as 40,000 in Luoshan station and Hankou station after optimal selection.

Correction of Backwater Effect of Downstream Branch Inflow

Effluents of drainage systems in the downstream of Luoshan station and Hankou station such as Lushui, Jinshui, Han River, eastern Hubei as well as Poyang Lake, etc. has backwater effect on water levels in the two stations to different degrees. Backwater effects of branches inflow and river channel damming effect elevate water levels in the two stations. [6]Hence, correction of backwater effect should be conducted, and the method is:

$$
Q_{n}=Q_{c}+\sum k_{i} q_{i}
$$

$Q_{n} \longrightarrow$ backwater jacking flow after correction $\left(\mathrm{m}^{3} / \mathrm{s}\right)$;

$Q_{c} \longrightarrow$ the flow after correction of the flood fluctuation rate $\left(\mathrm{m}^{3} / \mathrm{s}\right)$;

$q_{i}$ the jacking flow corresponding with all levels of a tributary from Luoshan to Hukou $\left(\mathrm{m}^{3} / \mathrm{s}\right)$;

$k_{i} \ldots$ jacking coefficient of water from tributary;

$i-$ ordinal number of the tributary.

With full consideration of the two main influencing factors-downstream branches backwater effect and flood fluctuation, water level-flow relations in Luoshan station and Hankou station were deduced as shown in Table 2 and Table 3. 


$\begin{aligned} & \text { Elow } \\ & \text { rate }\end{aligned}$
Watar

Table2 :The stage-discharge relationship results of Luoshan (water level: $\mathbf{m}$; flow rate: $\mathbf{m}^{3} / \mathrm{s}$ )

\begin{tabular}{cccccccccc}
\hline $\begin{array}{c}\text { Flow } \\
\text { rate }\end{array}$ & -0.8 & -0.4 & \multicolumn{7}{c}{ The fluctuation rate of Hankou } \\
$\begin{array}{c}\text { Water } \\
\text { level }\end{array}$ & & & -0.2 & 0 & 0.2 & 0.4 & 0.6 & 1 \\
17 & 13700 & 14000 & 14300 & 14700 & 15100 & 15400 & 15800 & 16900 \\
19 & 18100 & 19000 & 19500 & 20000 & 20500 & 21000 & 21600 & 23100 \\
21 & 22900 & 24500 & 25400 & 26100 & 27000 & 27900 & 28700 & 30500 \\
23 & 28700 & 30700 & 31800 & 33000 & 34100 & 35200 & 36300 & 39100 \\
25 & 36200 & 38800 & 40100 & 41700 & 43200 & 44600 & 46000 & 49400 \\
27 & 45200 & 48900 & 50500 & 52500 & 54000 & 56000 & 57500 & 62800 \\
28 & 51500 & 55000 & 57000 & 59200 & 61200 & 63000 & 64900 & 71500 \\
29 & 58300 & 62000 & 64200 & 66900 & 68900 & 71000 & 73400 & 80000 \\
30 & 64800 & 69600 & 72000 & 74800 & 77000 & 79500 & 82000 & 88100 \\
32 & 80700 & 85700 & 88300 & 91000 & 93500 & 95900 & 98700 & 104200 \\
\hline
\end{tabular}

Table3 :The stage-discharge relationship results of Hankou (water level: $\mathbf{m}$; flow rate: $\mathbf{m}^{3} / \mathrm{s}$ ) Principle of Polynomial Fitting Method

As there was a large quantity of calculation data with large fluctuation, and polynomial fitting method was suitable for analyzing deviations of a large quantity of data, it's even more suitable for situation with large data fluctuation. [7]Therefore, we used principle of the least squares method to establish polynomial fitting equation through deformation regression model:

$$
y=b+c_{1} x+c_{2} x^{2}+c_{3} x^{3}+\ldots \ldots+c_{n} x^{n}
$$

In order to select optimal fitting curve, parameter $R^{2}$ was taken to characterize reliability of fitted curve.

$$
\begin{aligned}
& R^{2}=1-\frac{S S E}{S S T} \\
& S S E=\sum\left(Y_{i}-\hat{Y}_{i}\right)^{2} \\
& S S T=\sum Y_{i}^{2}-\frac{\left(\sum Y_{i}\right)^{2}}{n}
\end{aligned}
$$

When $\mathrm{R}$ square value of fitted curve was equal to or approximate to 1 , its reliability was the highest. 


\section{Water Level-Flow Relation Curve Results and Reasonableness Analysis in Stations}

\section{Shashi Station}

The calculation in this paper mainly used flood data during 1981 2003 especially high water level data in Lianhuatang in 1983, 1996, 1998, 1999 and 2001 which could reflect water level-flow relation under current status in Shashi station. Based on measured water flow results in Shashi station, we analyzed and corrected flood fluctuation rate and water level backwater effect in Lianhuatang, after which we finally transformed them into Shashi water level-flow relation cluster which took water levels in Lianhuatang as parameters, [8] and then we obtained water level-flow relation curve results mapped out by hydrological data in Shashi station during1980 2003 as shown in Graph1.

\section{Graph1: The stage-discharge relationship curve of Shashi}

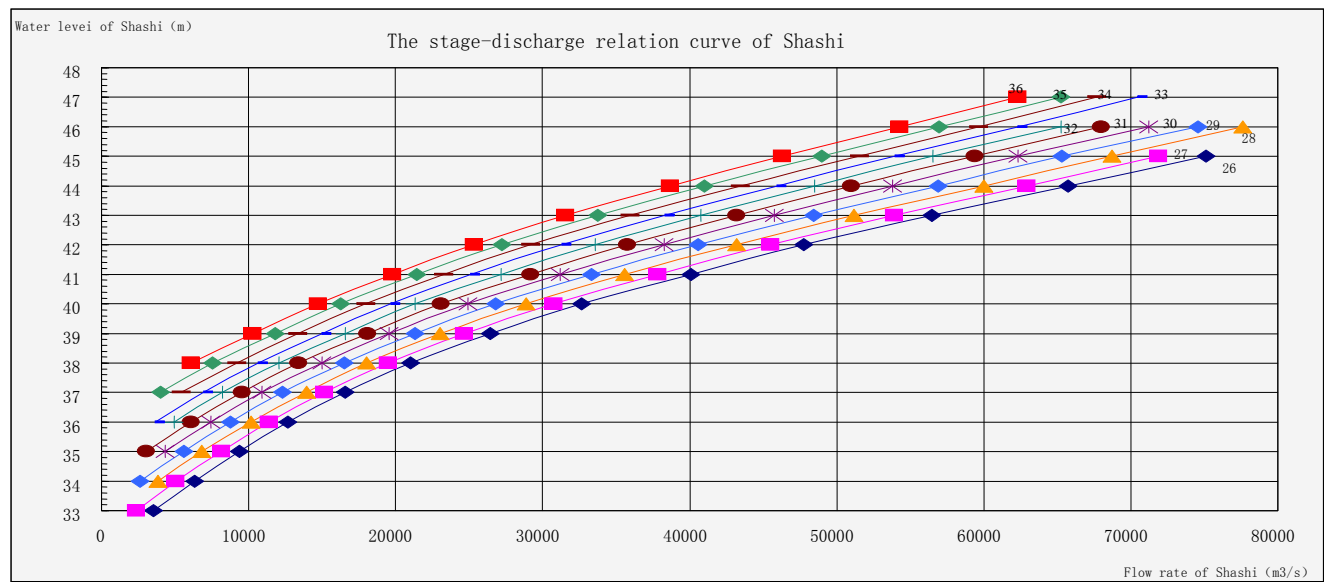

It can be seen from water level-flow relation curve that: when water level in Lianhuatang remained unchanged, Shashi water level-flow relation presented monotonic increasing relation line. When Shashi water flow was unchanged, Shashi water level would increase with water level in Lianhuatang elevated. Under the same water level in Shashi, Shashi water flow would increase as water level in Lianhuatang lowered and then it would tend to be stable.

\section{Luoshan Station and Hankou Station}

As stated above, there are many factors influencing water level-flow relations in Luoshan station and Hankou station. It's difficult to make quantitative analysis of effects of all factors. Hence, we analyzed main influencing factors of the two stations. We adopted measured water level and flow data over the years, firstly we used correction factor method to eliminate influence of flood fluctuation, then we conducted downstream backwater effect correction, and implemented a statistical analysis of comprehensive lines given by these years, and finally we obtained water level-flow relation curves which took fluctuation rates as parameters as shown in Graph2 and Graph 3.

\section{Graph2: The stage-discharge relationship curve of Luoshan}

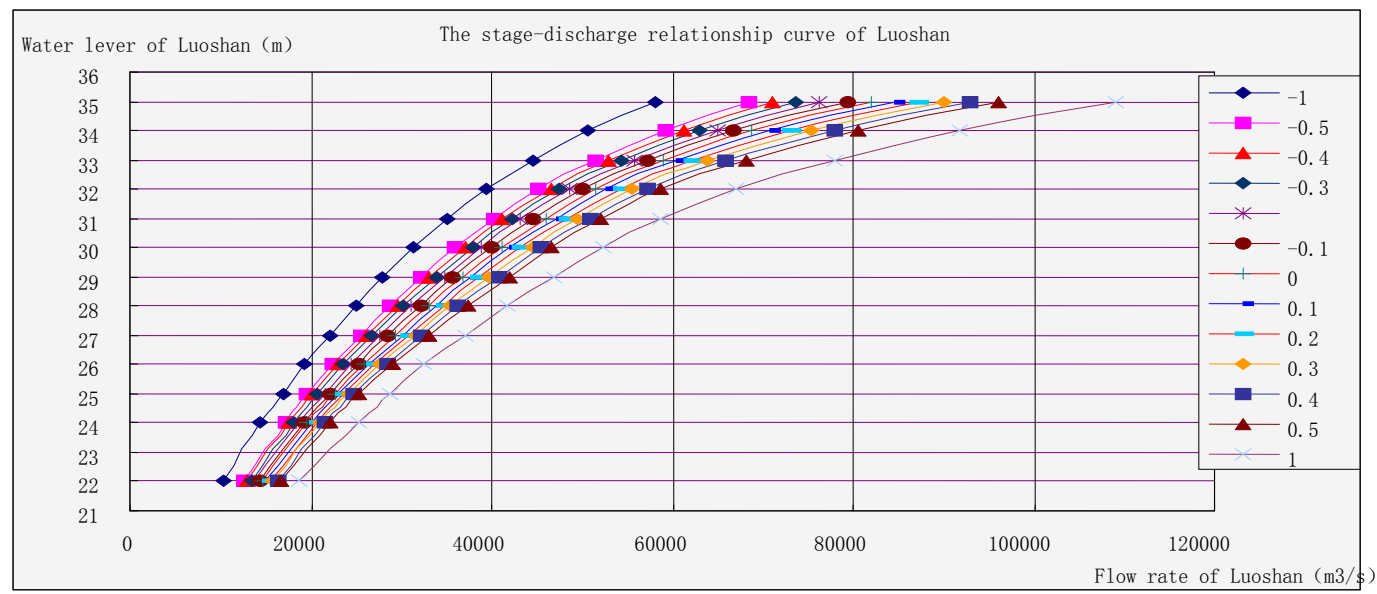


Graph3: The stage-discharge relationship curve of Hankou

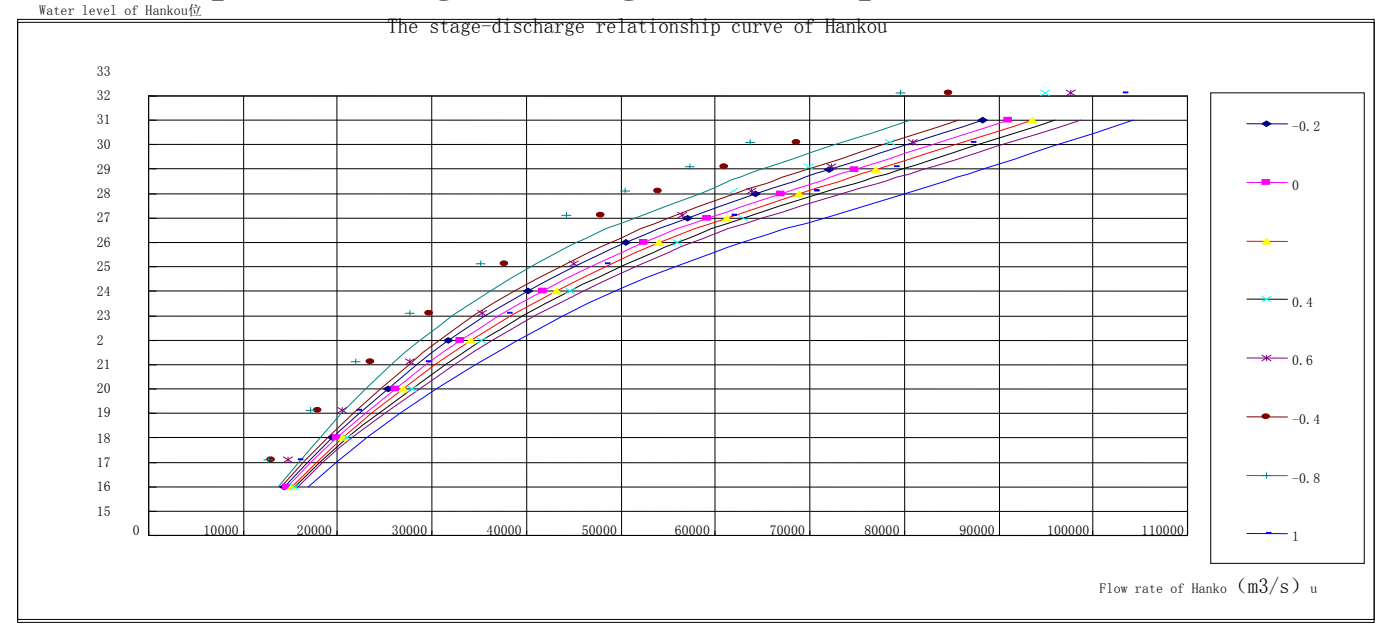

\section{Conclusion}

In order to verify reasonableness of water level-flow relation curves in stations obtained above, we selected measured data in 1998 to conduct verifying calculation, and specific verification method was:

(1) According to measured water levels and water level during flood rising as well as relevant parameters in these control stations, we checked and obtained Q through water level-flow relation curves;

(2) We conducted statistical analysis of errors of measured flow duration curves and calculated flow duration curves.

Analysis showed that: calculated flow conformed to measured flow very well, fitted water level-flow relation curves could accord with measured data in 1998, from which it could be seen that water level-flow relation obtained by uniformization processing of comprehensive fall index method was feasible.

The research analyzed hydrological characteristics in the middle reaches of Yangtze River, and it's especially of great significance to major problems such as river-lake relation, hydrological forecasting during flood period, river bed evolution after bend cutting of Jingjiang River, excess flood distribution and dispatch, etc.

\section{References}

[1] WU Shiyong, LIU Xiaoqion, PENG Yanming. Analysis and study for uniform ization of water level-discharge relation of Erlangji station on ChangJiang[J]. Yangtze River, 2010,21（41）:42-44 [2] LI Shiqiang, ZOU Hongmei. Analysis on water level-discharge relation of Luoshan hydrologic station in middle reaches of Yangtze River[J].Yangtze River,2011,6 (42):87-89

[3] LUAN Zhenyu, SHI Yong, CHEN Liangang.Analysis of water level and discharge wariation in middle Yangtze River after impoundment of TGP reservoir[J]. Yangtze River,2009,14 (40): :44-46 [4] SHI Xiuduan. Variation of the stage-discharge curves over years at three Yangtze hydrologic stations[J]. Yangtze River, 1993,7（24）: 43-48

[5] XIE Zuotao, ZHANG Xiaofeng, TAN Guangming. Forecasting of stage-discharge relationship of Luoshan on the Yangtze River[J].2005,2 (38):15-19

[6] HUANG Chengliang.Fall exponent method in uniformization treatment of water level and flow relation[J].Journal of ChangJiang Engineering Vocational Colledge,2010,2（27）:52-54

[7] GUO Xiwang, CHEN Jianchi, Zou Ning.Research on stage-discharge relation of main hydrologic stations on middle and lower reach of the Yangtze River[J]. Yangtze River,2006,9 (37):68-71 
[8] AN Lina, GE Shouxi. Discharge calculation from water level of gauging station influenced by backwater with water-head index method[J]. Yangtze River,2003,7（34） : 35-37 